\title{
CASE STUDY APPROACH TO TEACHING AND LEARNING ENGLISH FOR MEDICAL PURPOSES
}

\author{
Nataša Šelmić \\ Faculty of Medicine, University of Niš, Serbia
}

\begin{abstract}
The expression case study implies a wide range of issues presented for analysis, based on actual or simulated events that could logically occur. Besides, it involves profound research of phenomena or events. In medical education and practice, a case study represents an essential diagnostic procedure and investigation method used to create a profound understanding of an intricate problem in its real context. The implementation of the case study approach is of great importance in teaching English for medical purposes because the medical topics presented to students are familiar to them and medical terminology is applied to language learning. The case study is so structured as to serve the communicative function and provides the necessary content. It comprises the most relevant aspects in the field of medicine such as presenting signs and symptoms, performing different types of examinations, treatment, and health care management. The standard problem that needs to be solved is the patient's problem, and establishing an adequate diagnosis is the goal. In this way, students develop critical thinking and reflective learning, improve organizational skills, as well as the ability to see the complexity of real-world events and understand the perspective of others. This method has proven to be highly practical preparing students for reality, not theory workplace. In this way integration of language and the professional setting is enabled.
\end{abstract}

Key words: case study, English for medical purposes, communicative function, professional setting

\section{INTRODUCTION}

Bearing in mind that contemporary society is constantly changing and in line with this education is recognized as a continuing process, the application of contemporary principles and approaches to teaching English for specific purposes is of extreme importance. The main aim of education is the facilitation of learning and includes the ability to adopt changes according to the most prevalent demands of society. Long- term learning is the leading principle and is particularly relevant for the field of medicine that is rapidly growing. Therefore, all the courses designed for the medical field should rely on students' learning strategies and attempt to create students' autonomy. The expression case study implies a wide range of issues presented for analysis, based on actual or simulated events that could logically occur. Besides, it involves profound research of phenomena or events,

Submitted November $17^{\text {th }}, 2020$, accepted for publication February $23^{\text {rd }}, 2021$

Corresponding author: Nataša Šelmić. Faculty of Medicine, University of Niš, Dr. Zoran Đinđić Blvd. 81, 18000 Niš, Serbia|E-mail: natasaselmicmilosavljevic@gmail.com 
data collection, data analysis, and reporting of the obtained results. This methodological approach is applicable in many sciences and has a global, interprofessional role (Vaugeois, Nicole L., 2005:3). In medical education and practice, a case study represents an essential diagnostic procedure and investigation method used to create a profound understanding of an intricate problem in its realistic context. It is for this reason sometimes observed as a 'naturalistic' design; as opposed to an 'experimental' design in which the investigator has control over factors of interest (Crowe et al., 2011:100). A standardized case study has pedagogic utility, represents a general issue beyond the case itself, tells an engaging story, focuses on an interest-arousing, argumentative issue, presents a problem that has no apparent right answer, creates empathy with the central characters, demands the reader to process the information, encourages the reader to apply critical and analytical thinking, is concise, and is relevant to students (McFarlane, 2015).

\section{Advantages of Using the Case Study ApPROACH IN TEACHING ENGLISH FOR MEDICAL PURPOSES}

The implementation of the case study approach is of great importance in teaching English for medical purposes, because of the medical terms that are applied to language learning, and topics familiar to students discussed and analyzed. The case study is so structured as to serve the communicative function and provides the necessary content. It comprises the most relevant aspects in the field of medicine such as presenting signs and symptoms, performing different types of examinations, treatment, and health care management. In this way, students develop critical thinking and reflective learning, improve organizational skills as well as the ability to see the complexity of real-world events and understand the perspective of others. Moreover, they enhance communicative skills, cooperative learning, and team-work. (Dudley - Evans.and St John, 1998). This method has proven to be highly practical in preparing students for reality, not theory workplace (Mavor and Tayner. 2001: 346). In this way integration of language and professional setting is enabled (MacDonald et al, 2000, 260). The standard problem that needs to be solved is the patient's problem, and establishing an adequate diagnosis is the goal. Therefore, various in-class activities may include: pair and teamwork, discussions, presentations, and conference language. The students are divided into several groups with specific tasks practising asking and answering open and closed- ended questions, note-taking, note-making, as well as specialized vocabulary. Besides all these advantages the communicative function of the case study is explained - reporting factual data on medical cases. To completely accomplish it the topics about the disease, establishing the diagnosis and treatment, discussions considering symptoms and signs, as well as medical history taking motivate students to actively participate in the dynamic process of acquiring new knowledge (Kennedy, 2001: 120).

\section{In-CLASS ACTIVITIES BASED ON THE CASE STUDY APPROACH}

One of the important components of teaching Medical English is work in small groups in which each student gives his contribution. Some of the in-class activities include brainstorming, categorization, discussion, and concluding. The major advantages of teaching in small groups are encouraging students to express themselves and discuss 
directly, participate actively, and upgrade communication skills.Such an approach enables increased identification of the students' needs and the improvement of linguistic ability and interpersonal skills. Moreover, their inner potential through the practice of the so - called sub-skills consisting of analytical thinking, problem- solving, deduction, and use of imagination is enhanced. Subsequently, educators are expected to use different attitudes and approaches of students in various activities in class (Kayaoğlu and Akbaş, 2016: 70). The standard in-class activity implies the presentation of the patient to students. The problem being investigated is the patient's illness. Students are divided into several groups. Each group needs to come up with a specific problem. This situation simulates a medical presentation of the case. The first group of students does not identify the disease itself. This is the task of students from other groups. In this phase, the detailed use of specialized vocabulary is practised, and a carefully planned, well-organized, concise, and precise oral presentation is delivered. Then, students listening to the presentation and writing notes, ask questions about additional information that would help them identify the disease. After that, each group should write a report in response to the presentation. In this report, students should identify the disease, provide evidence for their opinion based on the information they received from the presentation, and based on what they discovered themselves. Writing notes in this phase is considered very important because it is a way to get as much important information as possible to identify the disease. Students should select, organize, and then review their notes. This approach increases the number of both relevant questions and answers. The numerous and specific questions in some way regulate and correct the presentation by pointing out its weaknesses and shortcomings. The next stage is report writing by the group giving the presentation, and the other groups read the report, comment, and provide feedback. Students critically consider the work of their colleagues, which is extremely efficient, because in such a way the accuracy and rhetorical efficiency of writing are checked. Students directly criticize the second group in case of wrong information, ambiguities, insufficient information, etc. The group giving the presentation has time to explain the reasons for their choice.

At this point, they also refer to the sources used. In this way, reference citations are practised. The last phase is the phase in which the group that prepared the presentation gives a critical review of the presentation. This is probably the most important phase in the learning process because students become aware of both good and bad sides of the project. The ability to criticize the work done is important and naturally arises from this approach, because cooperative learning is enhanced.

\subsection{Examples of a case study practised in class:}

Example 1

A 39- year-old woman working in a confectionery presents with a 2-year history of asthma and allergic rhinitis symptoms, including episodic cough, wheeze, shortness of breath with itchy red eyes, and a stuffy, runny nose. These symptoms worsened within 1-2 hours of starting work each day, and worsen throughout the working week. She especially finds fine flour to worsen her symptoms almost immediately on exposure. She feels better within 1-2 hours after leaving her work. She has been working in the confectionery for 15 years, and for the last 11 years has been weighing components, where exposure to dust has been higher than in other areas. Therefore, she has been wearing a mask all the time. 
As a child, she suffered from seasonal allergic rhinitis in the summer months. She is a non-smoker. Her mother and brother suffered from asthma. At present, she uses an inhaled steroid-long acting bronchodilator and an inhaled short-acting bronchodilator as needed. (* www.thoracic.com)

Based on the brief description of the patient and her symptoms, students create a model of the context of the situation through which they may predict possible problems and solutions to the case. Possible questions following the case study include: What questions might a doctor ask to obtain the information in the case history? Make a dialogue between a doctor and a patient. The basic communicative function of the case report is the presentation of factual data on past events and is achieved by using the past simple tense that plays a dominant role in the presentation of the case. The past perfect tense is used to express the sequence of past events and is most common in the part that describes the patient's medical history. The present perfect is used to explain the patient's past condition referring to the present moment, while the present tense is used to describe the patient's current condition. They are also used to make a final assessment of the treatment related to the present.

\section{Example 2}

In the case study below single out the verbs and determine the tenses and voice:

A 33 year-old man was referred to the ENT department after assessment at a district general hospital, with the symptom of sudden hearing loss in the left ear. The symptoms started within $12 \mathrm{~h}$ of receiving his second dose of rabies pretravel vaccination. The patient was feeling generally unwell and complained of worsening tinnitus accompanied by severe vertigo. He had no history of recent head injury, upper respiratory tract infection, or ototoxic medications, and was pain- free. He was known to have dietcontrolled type 2 diabetes mellitus and atopy. He had no regular medications and no known drug allergies. He had been started on high-dose prednisolone, acyclovir, and betahistine by the referring district general hospital's ENT department. The otoscopic examination confirmed normal external auditory canals and tympanic membranes bilaterally. There was no focal neurology (Saleh et al, 2015).

\section{Example 3}

Fill in the blanks with appropriate words:

A 33-year-old man to the ENT department after assessment at a district general hospital, with the of sudden hearing loss in the left ear. The symptoms within 12 h of receiving his second dose of rabies pretravel . The patient was feeling generally and of worsening tinnitus by severe vertigo. He had no ___ of recent head injury, upper respiratory tract infection, or ototoxic medications, and was pain -free. He was to have diet-controlled type 2 diabetes mellitus and atopy. He had no regular and no known drug allergies. He had been started on high-dose prednisolone, acyclovir and betahistine by the referring district general hospital's ENT department. The otoscopic confirmed normal external auditory canals and tympanic membranes bilaterally. There was no focal neurology. (Saleh et al., 2015) 


\section{CONCLUSION}

Case studies are considered to be an effective-based method for bridging the gap between theory and practice. They are used as part of an integrated approach for the development of applied knowledge based on analytical and critical thinking skills, and, therefore should be stimulating and motivating, thus creating an atmosphere for the enhancement of students' creativity. The content used during in-class activities is significant for academic setting and skills taught to students are the ones that are relevant for further professional improvement. The major advantage of using the case study approach is that activities used in class are student-centered and directed towards the implementation of theoretical concepts in the medical setting. Moreover, various possibilities of receiving adequate instructions for life-lasting education are provided, such as access to additional professional development opportunities and training abroad. Consequently, the involvement in the case method allows educators to develop a more profound understanding of their principles and instruction conceptions concerning the work setting. Having in mind that case studies offer a pedagogically reliable approach to promoting the acquisition of course content among future medical professionals and to fostering their professional development, educators should pay special attention to how the type and quality of the selected case study affect the teaching process

\section{REFERENCES}

Crowe, Sarah, Kathrin Cresswell, Ann Robertson, Guro Huby, Anthony Avery, and Aziz Sheikh. "The case study approach." BMC medical research methodology 11, no. 1 (2011): 100.

Dudley-Evans, Tony, Maggie Jo St John, and Maggie Jo Saint John. Developments in English for specific purposes: A multi-disciplinary approach. Cambridge university press, 1998.

Kayaoğlu, Mustafa Naci, and Raşide Dağ Akbaş. "An investigation into medical students' English language needs." Participatory Educational Research 3, no. 4 (2016): 63-71.

Kennedy, Miriam. "Teaching communication skills to medical students: Unexpected attitudes and outcomes." Teaching in higher education 6, no. 1 (2001): 119-123.

MacDonald, Malcolm, Richard Badger, and Goodith White. "The real thing?: authenticity and academic listening." English for Specific Purposes 19, no. 3 (2000): 253-267.

Mavor, Sally, and Beverly Trayner. "Aligning genre and practice with learning in higher education: An interdisciplinary perspective for course design and teaching." English for Specific Purposes 20, no. 4 (2001): 345-366.

McFarlane, Donovan A. "Guidelines for using case studies in the teaching-learning process." College Quarterly 18, no. 1 (2015): n1.

Saleh, Okhovat, Richard Fox, Jennifer Magill, and Antony Narula. "Sudden onset unilateral sensorineural hearing loss after rabies vaccination." Case Reports 2015 (2015).

Vaugeois, Nicole L. "Making the case for case study learning." Informed leisure practice (2005): 3. 